\title{
A validated methodology for the prediction of heating and cooling energy demand for buildings within the Urban Heat Island: case-study of London
}

\author{
Maria Kolokotroni $^{\mathrm{a}}$, Michael Davies ${ }^{\mathrm{b}}$, Ben Croxford ${ }^{\mathrm{b}}$, Saiful Bhuiyan ${ }^{\mathrm{a}}$, Anna \\ Mavrogianni ${ }^{\mathrm{b}}$
}

${ }^{a}$ Mechanical Engineering, School of Engineering and Design, Brunel University, Uxbridge, UB8 3PH, UK

${ }^{\mathrm{b}}$ The Bartlett School of Graduate Studies, University College London, London, UK

Email: maria.kolokotroni@brunel.ac.uk

\begin{abstract}
This paper describes a method for predicting air temperatures within the urban heat island at discreet locations based on input data from one meteorological station for the time the prediction is required and historic measured air temperatures within the city. It uses London as a case-study to describe the method and its applications. The prediction model is based on Artificial Neural Network (ANN) modelling and it is termed the London Site Specific Air Temperature (LSSAT) predictor. The temporal and spatial validity of the model was tested using data measured eight years later from the original dataset; it was found that site specific hourly air temperature prediction provides acceptable accuracy and improves considerably for average monthly values. It thus is a very reliable tool for use as part of the process of predicting heating and cooling loads for urban buildings. This is illustrated by the computation of heating degree days (HDD) and cooling degree hours (CDH) for a West-East transect within London. The described method could be used for any city for which historic hourly air temperatures are available for a number of locations; for example air pollution measuring sites, common in many cities, typically measure air temperature on an hourly basis.
\end{abstract}




\section{Introduction}

Urban warming, commonly referred to as the 'Urban Heat Island' phenomenon (UHI), is a well-established effect. The formation of distinct urban climates is mainly attributed to the urban-rural variation of a number of factors commonly linked with urbanisation; these include the thermal properties of surfaces, the urban morphology, and air pollution levels; (Oke 1987 and 1995). As a result of this variation, larger amounts of solar short wave radiation are captured, absorbed and stored in urban surfaces than in rural surfaces during the day. In addition, urban canyons are also characterised by smaller sky view factors and, thus, lower rates of long wave radiation loss during the night. The evaporative cooling potential of highly impermeable builtup areas is also limited. Anthropogenic heat emissions are also greater in cities. The formation of different types of heat islands and the differences between surface and air distribution has previously been described (Oke 1995).

The magnitude of the UHI has been studied mostly in terms of the temperature differences between rural and urban locations. The spatial and temporal distribution of the urban heat island intensity varies significantly between cities. In most cases, intensities typically peak several hours after sunset rendering the heat island essentially a night time phenomenon. There are many studies on the quantification of UHI in large cities and reviews on research in Europe and other areas have been published (for example Santamouris, 2007, Roth 2007, Memon et al, 2009).

This paper focuses on a temperate climatic region using London as a case-study, where temperature differences between core urban and surrounding rural locations of several ${ }^{\circ} \mathrm{C}$ are commonly observed. An extensive series of measurements were undertaken by (Watkins et al, 2002), illustrating in detail the spatial and temporal patterns of London's heat island. However, the relationship of the local temperature distribution with land use and building form is much less well understood (Kolokotroni and Giridharan, 2008, Giridharan and Kolokotroni, 2009).

The rise in external ambient temperatures in urban environments, compared to rural environments, is associated with a series of interconnected impacts: 
- Comfort: In buildings without air conditioning, comfort levels during the summer will tend to decrease. During the winter comfort will tend to increase.

- Energy: It is possible that in order to meet raised comfort requirements, the use of air conditioning systems will increase, followed by a rise in summer time energy use. However, heating loads during winter will tend to reduce.

- Health: There is a well established relationship between higher outdoor temperatures and the risk of heat-related mortality. However, the death toll due to cold during winter will tend to decrease with higher winter temperatures.

The above listed effects are being studied in the UK by a consortium of meteorologists, building scientists, urban modellers, planners, urban and building designers and epidemiologists to research how cities can adapt to a changing climate (LUCID, 2009). The work involves the development of urban climate models and energy models at a variety of scales - city, neighborhood, street and building. The suite of models are interrelated and have been described in (Mavrogianni et al, 2010). This paper focuses on one of the models; the London Site Specific Air Temperature (LSSAT). It describes the development of the model, present results of its validation by comparison with measurements and discuss its results and its application in the form of prediction of Heating and Cooling Degree Days.

For the prediction of urban air temperatures there exist a range of models varying in complexity and these were briefly reviewed in (Kolokotroni et al, 2006). These can be classified into the following four categories:

1. Climatology models, for example Taha 1999. A new model is recently being developed for London (Mavrogianni et al, 2010)

2. Empirical models using heat balance equations and empirically derived coefficients, for example the Cluster Thermal Time Constant model (CTTC) (Swaid and Hoffman, 1990) and further developed as the CAT model by Erell and Williamson (2006)

3. Computational Fluid Dynamics models, for example (Tabahashi et al 2004)

4. Statistical regression methods, probability methods and artificial neural networks, for example (Mihalakakou et al 2002) 
The model described in this paper is based on Artificial Neural Network (ANN) modelling and falls under category 4 of the above list. A description of the model was published in 2009 (Kolokotroni et al, 2009) and a summary is included in section 2 of this paper for completeness. Section 3 presents new data in the form of measurements carried out in 2008; these data were used to validate the model. Section 4 presents the computation of Heating Degree Days and Cooling Degree Hours for January and August for 20 locations on an East-West Transect of London for 2 years; 2000 which is the year of the original dataset and 2008 which is the year of the validation data. 


\section{The LSSAT model: existing study}

This section explains how LSSAT was developed; this was described first in (Kolokotroni et al, 2009) but a summary is included here for completeness. As reported before (Watkins, 2002), an extensive measuring campaign took place in 1999-2000, during which hourly air temperatures were measured in 77 locations with the Greater London Area (GLA) for approximately 16 months (to include two summers). These are the fundamental data to be used here for the development of the LSSAT model. The predictions of these models for a given Fixed Temperature Station (FTS) together with the description of the FTS in terms of its urban on site characteristics as reported in (Kolokotroni and Giridharan, 2008) can be used to extrapolate for other locations and times.

The LSSAT model is an Artificial Neural Network (ANN) model and was developed using MATLAB 6.5 (2004). In general, the neural network architecture procedures on which the model is based could be divided into the following steps:

1. Design the neural network: select the type of the network and input parameters and determine the structure and number of layers and neurons.

2. Train the network: conduct the learning or training process.

3. Test and diagnostic check: carry out the simulation result analysis.

4. Optimization of the neural network by trial and error: compare the different types of network models and choose the best one as the final solution.

The implementation of these steps for the development of the LSSAT model is explained in summary in the following paragraphs and is explained more fully in (Kolokotroni et al 2009, Zhang 2008).

For the model, it is important to select an appropriate algorithm which fits the specific purpose of the problem in order to get the best performance for the simulation and prediction. The aim of the present work is to simulate urban air temperature as a function of weather conditions (these are further explained in the following paragraph); therefore the problem belongs to function approximation category. Previous work has concluded that two neural network algorithms are suitable: back- 
propagation and radial basis networks. Radial basis networks have a major disadvantage; slow operation due to the large number of neural networks to be trained, in this case 24 neural network models for each of the 77FTS. Therefore, back-propagation has been considered first which has also been used by other researchers studying similar problems (Livada et al 2002 and Mihalakakou et al 2004).

Generally, the back-propagation network consists of three parts; input layers, hidden layers and output layers. To build such a neural network model, we need to determine the input parameters; these are the region's weather related parameters. It has been reported by many researchers including work for London (Kolokotroni and Giridharan, 2008) that sky and wind conditions are closely related to the formation of UHI. The input parameters to represent these in the modelling are hourly values of global solar radiation on a horizontal surface, cloud cover and wind speed as measured at the meteorological station (Heathrow). In addition, hourly values of air relative humidity are used as a further input parameter as it has been found that there is a negative correlation with UHI intensity (Kim and Baik, 2002). Finally, the met station's hourly air temperature is the most important input parameter from which the FTS air temperature is derived. These input parameters have been termed off-site climate parameters as they represent the general climate of the region.

The output parameter is the hourly air temperature of the FTS.

As reported in (Kolokotroni et al, 2009) suitable back-propagation network, training method, error goal, maximum training epoch were selected by trial-and-error to give best correlation coefficients and minimum mean square error. The selected parameters are presented in Table 1.

The model for one location was first built and tested. This was carried out as follows: there are 77 FTS with the sufficient history data to build the LSSAT models and the database can be divided into three parts:

1. Hourly air temperature measured at each FTS,

2. Hourly air temperature of a convenient meteorological station; in this case Heathrow has been chosen because Heathrow's weather data are routinely used 
by designers and it is one of the four main met stations referred to by CIBSE (CIBSE 2006b)

3. Hourly weather data provided by the same meteorological station; these include hourly values of

$\circ$ Air temperature $\left({ }^{\circ} \mathrm{C}\right)$

- Air Relative humidity (\%)

○ Cloud cover (oktas)

- Air speed $(\mathrm{m} / \mathrm{s})$

- Global Solar Radiation on a horizontal surface $\left(\mathrm{W} / \mathrm{m}^{2}\right)$

In order to test the different networks and find the most suitable one, it was decided to select one FTS as a sample to test the method. North Road (located $3.2 \mathrm{~km}$ (2 miles) north of the central point which is the British Museum for the measured data) has been chosen due to the following reasons:

1. There is full historical hourly data of this station; from 1999 to 2000,427 days data totally.

2. The average urban heat island intensity measured in this station for the six hottest days among the 427 days (Graves et al, 2001), is nearly the average value among all FTS.

From the data available totally for training and testing, three quarters of the data (randomly selected) were used for training, and the rest for testing; this is a commonly used division for training purposes.

Using function and parameters as presented in Table 1, these were applied to the 24 hrs of the chosen FTS (North Road) and the prediction result is presented in Table 2 using three parameters; relative error (RE) in \%, the square of Pearson correlation coefficient $\left(\mathrm{r}^{2}\right)$ and mean square error (MSE). It can be seen that all hourly networks achieve a very good correlation coefficient. Mean square error varied between 0.2 and 0.6 , and relative error varied between $2.7 \%$ and $5.6 \%$. The best prediction result is for 21:00 hrs, while the worst one is for 14:00hrs. In general, the prediction result for night time (considered from 19:00 - 06:00) is much better than for the day time (considered from 07:00 - 18:00). The mean relative error for night time is $3.46 \%$ while for day time is $5 \%$, the mean correlation coefficient for night time is 0.99 while 
for day time is 0.98 , the mean square error for night time is 0.33 while for the daytime is 0.54 .

The procedure described above was repeated for all FTSs and LSSAT models were developed for the 77 FTS. It should be noted that some of the networks perform better than others; this is because of data availability for training - in some of the stations key periods of data were missing and therefore the network prediction is not as accurate as locations where full datasets were available. 


\section{Validation of the model}

\subsection{New data: Measurements of air temperature in London in}

2008

As expected, the predictions of LSSAT model are very accurate for 1999/2000 period as reported in (Kolokotroni et al, 2009) which is the year of the original measured data.

Hourly air temperature measurements were repeated using exactly the same equipment and methodology in 2007/8 for a selection of nine locations (including the reference cite) with the aim of validating the LSSAT model and also to study whether any difference can be observed between 2000 and 2008. The locations of new measurements are shown in Figure 1, which also presents the location of the 1999/2000 measurements.

Air temperature data were collected on an hourly basis data using Tinytalk loggers mounted on lamp post at a height approximately $6 \mathrm{~m}$ above the ground. Figure 2 shows a diagrammatic cross-section and a photograph of the air temperature measuring device (Watkins et al 2002). The Tinytalk was placed inside a white painted solar shield. The $6 \mathrm{~m}$ height was selected largely on security concerns and restrictions imposed by the local authorities. Also, at this height, they were away from local sources of heat (parked cars, etc.), but were accessible from ground level for data transcription. At the reference location, identical sensor housings were used, but attached to dead trees rather than lighting columns. The data-loggers used were battery-powered miniature loggers, $35 \mathrm{~mm}$ long. These have a quoted accuracy of $\pm 0.2 \mathrm{~K}$ with a resolution of $\pm 0.25 \mathrm{~K}$, but all loggers were inter-compared and individual calibrations determined so that the data from all loggers could be normalized to the mean of the distribution. Thus, mean temperature differences have an accuracy of about $\pm 0.1-0.2 \mathrm{~K}$ (a residual inaccuracy that exists because of a very small logger drift over time). 


\subsection{Comparison of predictions with measurements}

LSSAT was used to predict hourly air temperature for the year for the eight urban locations and the reference location (Langley country Park) of the new measurements. The input weather data of air temperature, relative humidity, cloud cover, air speed and global solar radiation were acquired by the Meteorological Office for Heathrow.

A typical graph for 10 days at the end of July 2008 is shown in Figure 3 as an example. The graph includes hourly air temperatures from Heathrow (met data), measured and predicted hourly air temperatures for a central London location. It can be observed that there is a variation between predictions and measurements but the overall trend is predicted. The variation on the accuracy of the prediction can be attributed to differences in weather conditions between the target and training day due to the nature of the model. For example, if the target (prediction) day is cloudy and the training day was with clear sky then some inaccuracy will occur. For further development of similar models, it might be better to train the ANN for specific bands of external conditions (rather than actual days) and a suitable model would be selected depending on the meteorological input data.

The LSSAT model's hourly predictions for May 2008 were compared with LondUM (climatology model) with encouraging results (Mavroganni et al, 2010). For the hourly predictions, smoothing has been applied by averaging the predictions of three consequent predicted hourly values. This was necessary as the raw predictions were noisy; this again could be attributed to differences in weather conditions between the target and training hour.

Table 3 presents the results of simple statistical analysis of the predictions for four months (January/February and July/August) for the eight locations for which measurements are available and the reference location. The first row shows the distance from the centre point and the second a code indicating their relative position to the centre (ie NW would indicate that the location is north west to the centre). The third row gives the square of the Pearson correlation coefficient $\left(r^{2}\right)$ between measured and predicted values for the whole year. The following rows give the 
values of $\mathrm{r}^{2}$ for the four months and also separately for day and night. In addition, average measured and predicted air temperature is presented for each month. Blank cells exist because measured data was missing. The cells highlighted with grey are based on limited data and therefore less confidence can be put on the values presented. The final rows of Table 3 give information of Heathrow weather data for the years of 2000 and 2008 which is useful to understand the climate difference in the two years considered in this study. It gives some background information related to analysis presented in section 4 .

From the results presented in Table 3, the following can be observed:

- The predicted and measured monthly average temperature compare very favourably. This result gives confidence in the ability of the LSSAT model to be used for the prediction of annual and monthly energy demand calculations.

- Monthly correlation coefficients are encouraging, in particular during the night which gives confidence in using the LSSAT model to predict UHI which is primarily a nocturnal phenomenon. 


\section{Results and discussion: London HDD and CDH in 2000 and 2008}

Taha (Taha1997) has argued that 'depending on geographic location and prevailing weather conditions, heat islands may be beneficial or detrimental to the urban dweller and energy user. Generally speaking, low and mid-latitude heat islands are unwanted because they contribute to cooling loads, thermal discomfort, and air pollution whereas high latitude heat islands are less of a problem because they can reduce heating energy requirements. This is a generalization however; the actual impacts of urban climates and heat islands depend on the characteristics of local climates. One way of indirectly characterizing these impacts is to examine heating and cooling degree-days data. Taha et al (1997) have shown that with respect to rural surrounds, urban areas have fewer heating degree days (HDD) but more cooling degree-days (or hours) (CDD-CDH). The work included cities with hot and cold weather conditions and it was shown that the effect is larger in hot climates but also observed in cold cities. The work also shown that for the cities examined, the effect of HDD and CDD modification by urban areas is an increase in cooling loads. The term cooling degree hours $(\mathrm{CDH})$ is used for high latitudes because of the low cooling demand in comparison to heating.

HDD and CDH were calculated using LSSAT predictions for 23 locations along the West-East axis of London. The results of the calculations are presented in Figures 4-7 for the months of July/August representing summer and January/February representing winter. The results for the years 2000 and 2008 are shown for comparison; calculations are based on hourly air temperature predictions for both years.

Figure 4 presents the $\mathrm{CDH}$ for July and August in 2008 calculated from air temperature predictions using LSSAT; the CDH for Heathrow are 4481 for July and 3974 for August 2008 calculated from met data; some details on the weather trends are shown in Table 3. For the calculations presented in this paper, a base temperature of $12{ }^{\circ} \mathrm{C}$ was used as this is commonly used in the UK for air-conditioning load calculation of generic buildings (CIBSE, 2006). The choice of $12{ }^{\circ} \mathrm{C}$ as base temperature for $\mathrm{CDH}$ assumes an all-air cooling system and is based on the air temperature at the cooling coil. For other systems, different base temperatures can be 
selected; with reference to free-floating buildings in hot climates the base temperature could be as high as $25^{\circ} \mathrm{C}$.

For comparison across time Figure 6 presents CDH for July and August in 2000 calculated in exactly the same manner as for 2008. The CDH for Heathrow are 3475 for July and 4590 for August 2000 calculated from met data; therefore August was the hottest month in 2000 with similar CDHs as July 2008.

For both years, the shape of CDH over London is similar with the highest point $3 \mathrm{~km}$ east of the original measurement centre (British Museum) and is placed in the City of London; this is termed thermal centre. In numerical terms for both 2000 and 2008, during the hot months of the summer, CDHs drop by 30-35 per $\mathrm{km}$ to the east and west of the thermal centre for about $15 \mathrm{~km}$.

Figures 5 and 7 present the HDD for January and February in 2000 and 2008 calculated to the base of $15.5^{\circ} \mathrm{C}$. The HDD for Heathrow are 240 for January and 253 for February calculated from met data in 2008. The HDD for Heathrow are 304 for January and 231 for February for 2000. Again in this case, February in 2008 and January in 2000 were the coldest months.

We can observe that in this case too, the thermal centre is $3 \mathrm{~km}$ east of the measurement centre, and heating demand is higher to the west of the thermal centre. In numerical terms, HDD reduce between 1.5 and 3 per $\mathrm{km}$ from the thermal centre and the offset value will depend on the severity of the weather.

Degree days are used in many cases for calculation of heating and cooling consumption of real buildings and notional buildings making some assumption about the building's heat losses/gains and base temperatures. As outlined in (CIBSE 2006), assuming that the building is heated continuously, the monthly heating energy consumption can be calculated by

$$
F_{H}=\frac{U^{\prime} \times H D D \times 24}{\eta} \mathrm{kWh}
$$


HDD = heating degree days multiplied by 24 to convert to hrs

$\eta=$ is overall seasonal heating system efficiency,

$U^{\prime}$ is overall building heat loss coefficient $(\mathrm{kW} \cdot \mathrm{K})$, given by:

$U^{\prime}=\frac{A \times U+\frac{1}{3} \times N \times V}{1000}$

where

$U$ is the fabric $U$-value $\left(\mathrm{W} \cdot \mathrm{m}^{-2} \cdot \mathrm{K}^{-1}\right)$,

$A$ is the component area $\left(\mathrm{m}^{2}\right)$,

$N$ is the air infiltration rate in air changes per hour $\left(\mathrm{h}^{-1}\right)$ and

$V$ is the volume of the space $\left(\mathrm{m}^{3}\right)$. (Note: the numerical factor $1 / 3$ arises from typical values of density and specific heat of air, and the conversion to air changes per hour (CIBSE 2006)).

In order to calculate the cooling load, the calculation is dependent on the cooling system but assuming an all-air air-conditioning system, the base temperature of $12^{\circ} \mathrm{C}$ is with reference to the cooling coil; in this way the cooling degree-hours are the effective summation of temperature difference across the coil. Therefore, they can be multiplied by the mass flow and these are specific heat of the air and then divided by the COP (coefficient of performance) of the chiller to calculate the energy and fuel consumption.

Therefore the cooling energy can be calculated by:

$F_{C}=\frac{m \times c_{p} \times C D H}{C O P} \mathrm{kWh}$

where

$\mathrm{CDH}=$ cooling degree hours

$\mathrm{COP}=$ is overall seasonal heating system efficiency,

$\mathrm{c}_{\mathrm{p}}=$ the specific heat of air $\mathrm{kJ} \cdot \mathrm{kg}^{-1}$, and

$\mathrm{m}=$ the mass flow rate $\mathrm{kg} \cdot \mathrm{s}^{-1}$

Both the equation above, indicate that heating and cooling energy consumption is proportional to degree days. For the months of January/February (heating) and July/August (cooling) for the year of 2000 and 2008 the ratio of heating and cooling 
degree days to the degree days of the reference site are presented in Figures 8 and 9. It can be observed that depending on the severity of the weather (as indicated by the degree days), heating energy consumption in central London is $65-85 \%$ of the heating required for the same building based outside the urban heat island. Cooling energy consumption is $32-42 \%$ higher than cooling energy required for the same building based outside the urban heat island. In terms of environmental impact (CO2 emissions) the difference is greater for countries (like the UK) where the fuel for heating is gas while electricity is used for cooling; the conversion factors currently used for benchmarks in the $\mathrm{UK}$ are $0.190 \mathrm{kgCO}_{2} / \mathrm{kWh}$ for gas and $0.550 \mathrm{kgCO}_{2} / \mathrm{kWh}$ for electricity (CIBSE 2009). 


\section{Conclusions}

This paper describes a validated method for predicting air temperatures within the urban heat island at discreet locations based on input data from one meteorological station for the time the prediction is required and historic measured air temperatures within the city. It uses London as a case-study to describe the method and its applications. The described prediction model is termed the London Site Specific Air Temperature (LSSAT) and comprises of a suite of Artificial Neural Network (ANN) models to predict site specific hourly air temperature within the Greater London Area (GLA). The model was developed using a back-propagation ANN model based on hourly air temperature measurements at 77 fixed temperature stations (FTS) and hourly meteorological data (off-site variables) from Heathrow. The hourly meteorological data required for the predictions are air temperature, relative humidity, cloud cover, wind speed and global solar radiation.

Comparisons of the LSSAT prediction with measured data in 2008 in eight locations (plus reference location in a park outside the city) has shown that the model is capable of reproducing the main features of air temperature trends on an hourly basis across London and it is highly accurate for monthly average temperatures. It should be noted that the model will not be as accurate for any year as for the training period (1999/2000 in this case) irrespectively if the prediction period is before or after. Its accuracy will not be reduced by steadily increasing (or decreasing) temperatures due to climate change because such changes will occur throughout the region including the location of weather data. However, the accuracy might reduce by abnormal weather conditions due to climate change, for example increased cloud cover.

Because of the accuracy in predicting monthly average temperatures, the model can be very useful in the calculation of heating and cooling loads for buildings within the urban area; in this paper this is demonstrated by calculating Heating Degree Days and Cooling Degree Hours for sample base temperatures. In the sample results presented in this paper, it was shown that distance from physical centre or thermal centre of London is one of the main factors affecting heating and cooling loads and thus the effect of urbanization on energy demand. 
The described method can be applied to other cities using air temperature data historical data in many cases available through air pollution networks or meteorological stations within cities.

\section{Acknowledgments}

This work is supported by the Engineering and Physical Science Research Council of the UK (EPSRC Grant No EP/E016308/1 (Brunel) and Grant EP/E016375/1 (UCL)). This work would not be possible without the contribution of Giridharan Renganathan (Brunel) James Milner, Zhihui Ye and Ian Hamilton (UCL) who contributed to the collection of the temperature measurements in 2008. 


\section{List of References}

CIBSE (2008). Energy Benchmarks, TM46, CIBSE, UK.

CIBSE (2006). Degree days: theory and application, TM41, CIBSE, UK

CIBSE (2006b), Guide J, Weather, Solar and Illuminance Data, CIBSE, UK.

Erell E and Williamson T (2006). Simulating air temperature in an urban street canyon in all weather conditions using measured data at a reference meteorological station, International Journal of Climatology, Vol 26, 1671-1694.

Giridharan R and Kolokotroni M, (2009). Urban heat island characteristics in London during winter. Solar Energy, Volume 83, Issue 9, September 2009, pp 1668-1682

Graves H, Watkins R, Westbury P, Littlefair P, (2001). Cooling Buildings in London - Overcoming the heat island, BR431, CRC.

Kim Y H and Baik J J, (2002). Maximum urban heat island intensity in Seoul. Journal of Applied Meteorology. Vol 41 (6), 651-659.

Kolokotroni M and Giridharan R, (2008). Urban Heat Island Intensity in London: An investigation of the impact of physical characteristics on changes in outdoor air temperature during summer, Solar Energy Vol 82, pp. 986-998

Kolokotroni M and Giridharan R, (2008). Urban Heat Island Intensity in London: An investigation of the impact of physical characteristics on changes in outdoor air temperature during summer, Solar Energy Vol 82, pp. 986-998

Kolokotroni M, Zhang Y and Giridharan R (2009), Heating and cooling degree day prediction with the London urban heat island, Building Services Engineering Research and Technology, Vol 30, No 3, pp183-202.

Kolokotroni M, Zhang Y and Watkins R, (2007), The London Heat Island and building cooling design, Solar Energy, Vol 81 pp 102-110.

Kolokotroni M, Zhang Y and Watkins R, (2007), The London Heat Island and building cooling design, Solar Energy, Vol 81 pp 102-110.

Livada I, Santamouris M, Niachou K, Papanikolaou N and Mihalakakou G (2002), Determination of places in the great Athens area where the heat island effect is observed, Theoretical Appl. Climatol., 71, 219-230

LUCID (2009). The Development of a Local Urban Climate Model and its Application to the Intelligent Design of Cities; http://www.lucid-project.org.uk/

MATLAB 6.5, User Guide, 2004.

Mavrogianni A, Davies M et al, (2009). The comfort, energy and health implications of London's urban heat island, Building Services Research and Technology, submitted. 
Memon RA, Dennis Y.C. Leung DYC and Liu C-H (2009) An investigation of urban heat island intensity (UHII) as an indicator of urban heating, Atmospheric Research 94 pp491-500

Mihalakakou G, Flocas H A, Santamouris M, Helmis C G, (2002). Application of Neural Networks to the Simulation of the Heat Island over Athens, Greece, Using Synoptic Types as a Predictor. Journal of Applied Meteorology. Vol 41, 519-527.

Mihalakakou G., Santamouris M., Papanikolaou N., Cartalis C and Tsangrassoulis A., (2004) Simulation Of The Urban Heat Island Phenomenon In Mediterranean Climates, Pure Appl. Geophys. 161, 429-451

Oke TR.(1987) Boundary layer climates. Routledge.

Oke, T.R., (1995). The heat island of the urban boundary layer: characteristics, causes and effects. In Cermak, J.E., Davenport, A.G., Plate, E.J, Viegas, D.X. (Eds.), Wind Climate in Cities. NAASI series. Kluwer Academic Publishers, Dordrecht, pp. 81107.

Roth M, (2007) Review of urban climate research in (sub) tropical regions, International Journal of climatology, Vol 27, Issue 14, Pages 1859-1873.

Santamouris M, (2007). Heat Island Research in Europe - The State of the Art, Advances in Building Energy Research (ABER) Vol 1 (1), pp123-150, Earthscan

Swaid H, Hoffman M E, (1990a). Prediction of Urban air temperature variation using the analytical CTTC model. Energy and Buildings Vol 14 p313-324.

Tabahashi K, Yoshida H, Tanaka Y, Aotake N and Wang F (2004). Measurements of thermal environment in Kyoto city and its prediction by CFD simulation. Energy and Buildings, Vol 36, Issue 8, pp771-779.

Taha H (1997). Urban climates and heat islands: albedo, evapotranspiration, and anthropogenic heat, Energy and Buildings 25 ( 1997) 99-103

Taha H. (1999). Modifying a mesoscale meteorological model to better incorporate urban heat storage: A bulk-parameterization approach. Journal of applied meteorology 38(4): 466-473 APR 1999.

Watkins R, Palmer J, Kolokotroni M, Littlefair P. (2002). The London Heat Island: results from summertime monitoring. Building Services Engineering Research \& Technology. 23(2): 97-106.

Watkins R. (2002). The impact of the urban environment on the energy used for cooling buildings. PhD thesis, Brunel University

Zhang, Y (2008). Prediction of Urban Heat Island Intensity in London, PhD thesis, Brunel University 


\section{List of figures}

Figure 1: The fixed temperature stations of the LSSAT model along the eight transects of the Greater London Area. Measurement locations in 2008 are marked with squares.

Figure 2: A diagrammatic cross-section and a photograph of the air temperature measuring device (Watkins et al 2002)

Figure 3: Comparison of hourly predictions with measurements for 10 days at the end of July 2008. Heathrow temperature which is used as an input to the LSSAT model is shown.

Figure 4: Cooling degree hours for July and August in 2008 (base $12{ }^{\circ} \mathrm{C}$ ) calculated from air temperature predictions using LSSAT. The CDH for Heathrow are 4481 for July and 3974 for August calculated from met data.

Figure 5: Heating degree days for January and February in 2008 (base $15.5^{\circ} \mathrm{C}$ ) calculated from air temperature predictions using LSSAT. The HDD for Heathrow are 240 for January and 253 for February calculated from met data.

Figure 6: Cooling degree hours for July and August in 2000 (base $12{ }^{\circ} \mathrm{C}$ ) calculated from air temperature predictions using LSSAT. The CDH for Heathrow are 3475 for July and 4590 for August calculated from met data.

Figure 7: Heating degree days for January and February in 2000 (base $15.5^{\circ} \mathrm{C}$ ) calculated from air temperature predictions using LSSAT. The HDD for Heathrow are 304 for January and 231 for February calculated from met data.

Figure 8: Ratio of Heating and Cooling Degree Days to Reference Site Degree Days for a West-East Transect of London in 2000. The graphs indicates relative heating and cooling energy consumption within the urban heat island compared to the reference rural locations based on air temperature prediction using the model LSSAT. 
Figure 9: Ratio of Heating and Cooling Degree Days to Reference Site Degree Days for a West-East Transect of London in 2008. The graphs indicates relative heating and cooling energy consumption within the urban heat island compared to the reference rural locations based on air temperature prediction using the model LSSAT.

\section{List of Tables}

Table 1: Parameters used for the development of the LSSAT model.

Table 2: Summary of the prediction result for hourly LSSAT models (North Road)

Table 3: Analysis of comparison between measured and predicted air temperatures for nine locations for July/August and January/February 2008. 


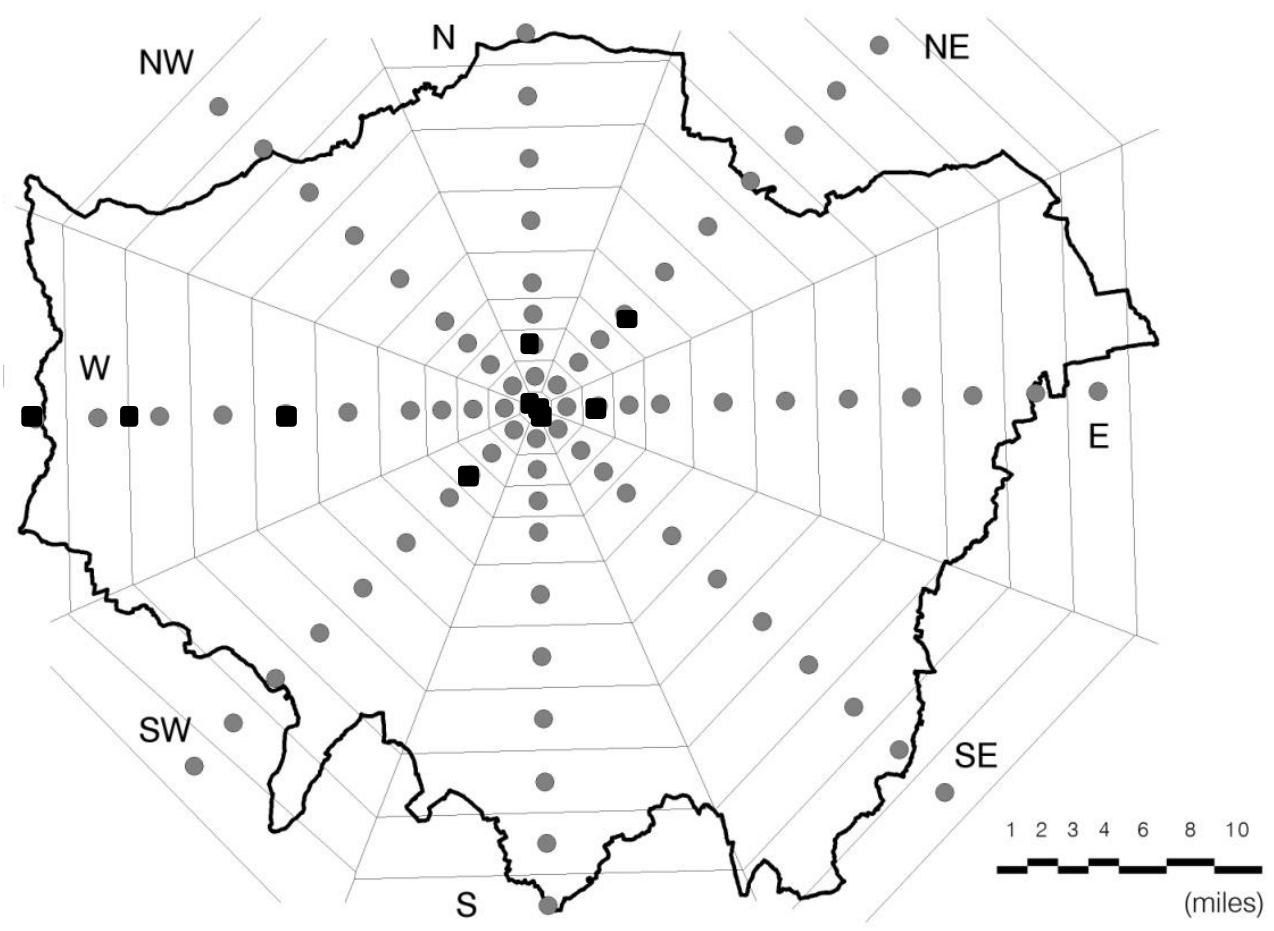

Figure 1: The fixed temperature stations of the LSSAT model along the eight transects of the Greater London Area. Measurement locations in 2008 are marked with squares. 


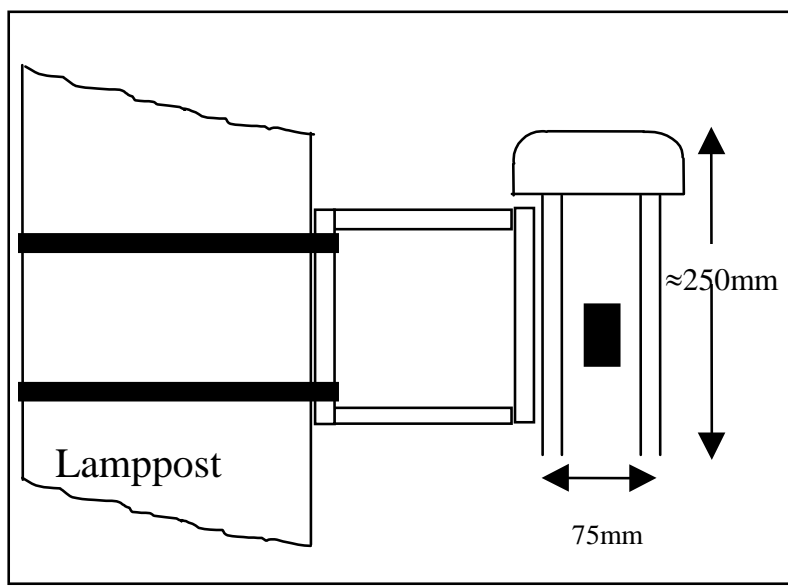

Figu re 2:

A diag

rammatic cross-section and a photograph of the air temperature measuring device (Watkins et al 2002)

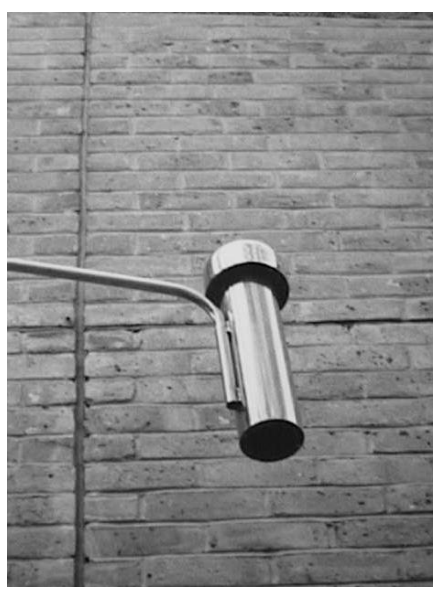




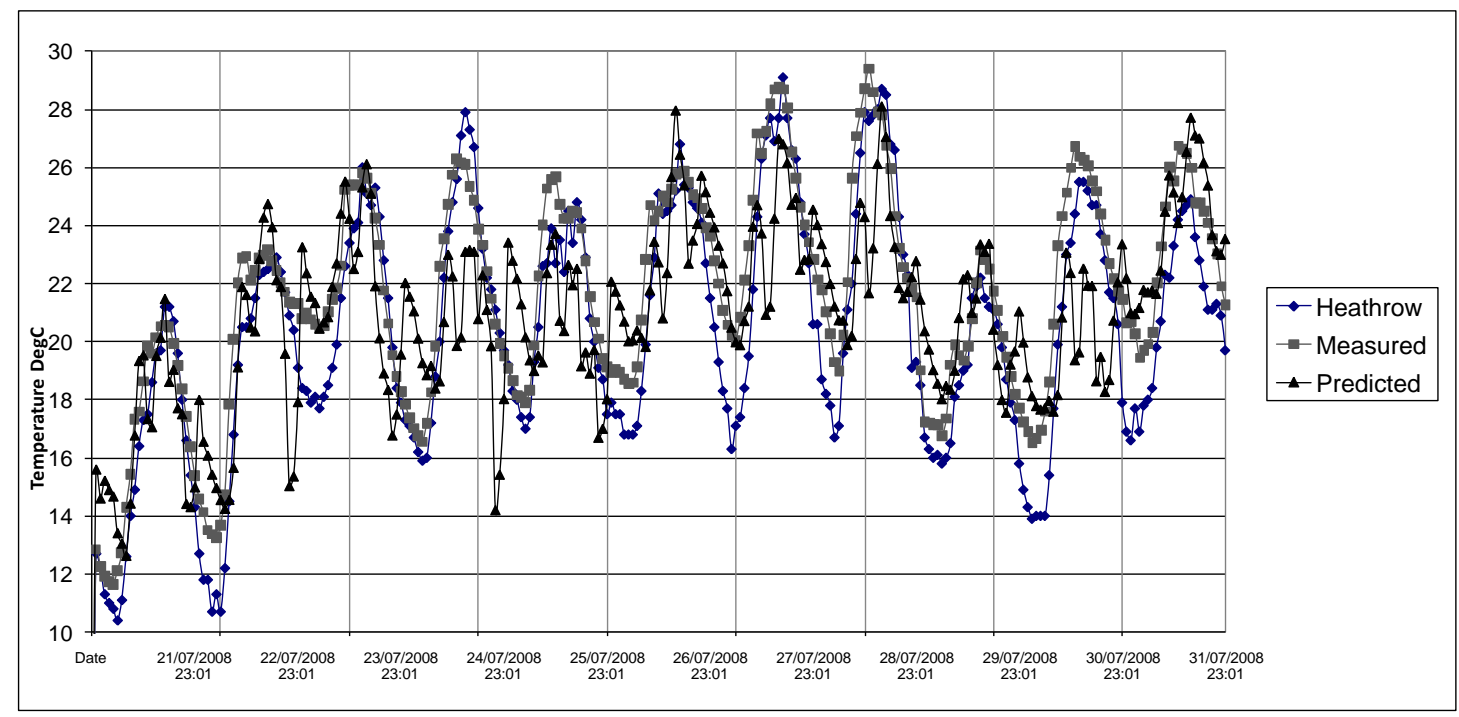

Figure 3: Comparison of hourly predictions with measurements for 10 days at the end of July 2008. Heathrow temperature which is used as an input to the LSSAT model is shown. 


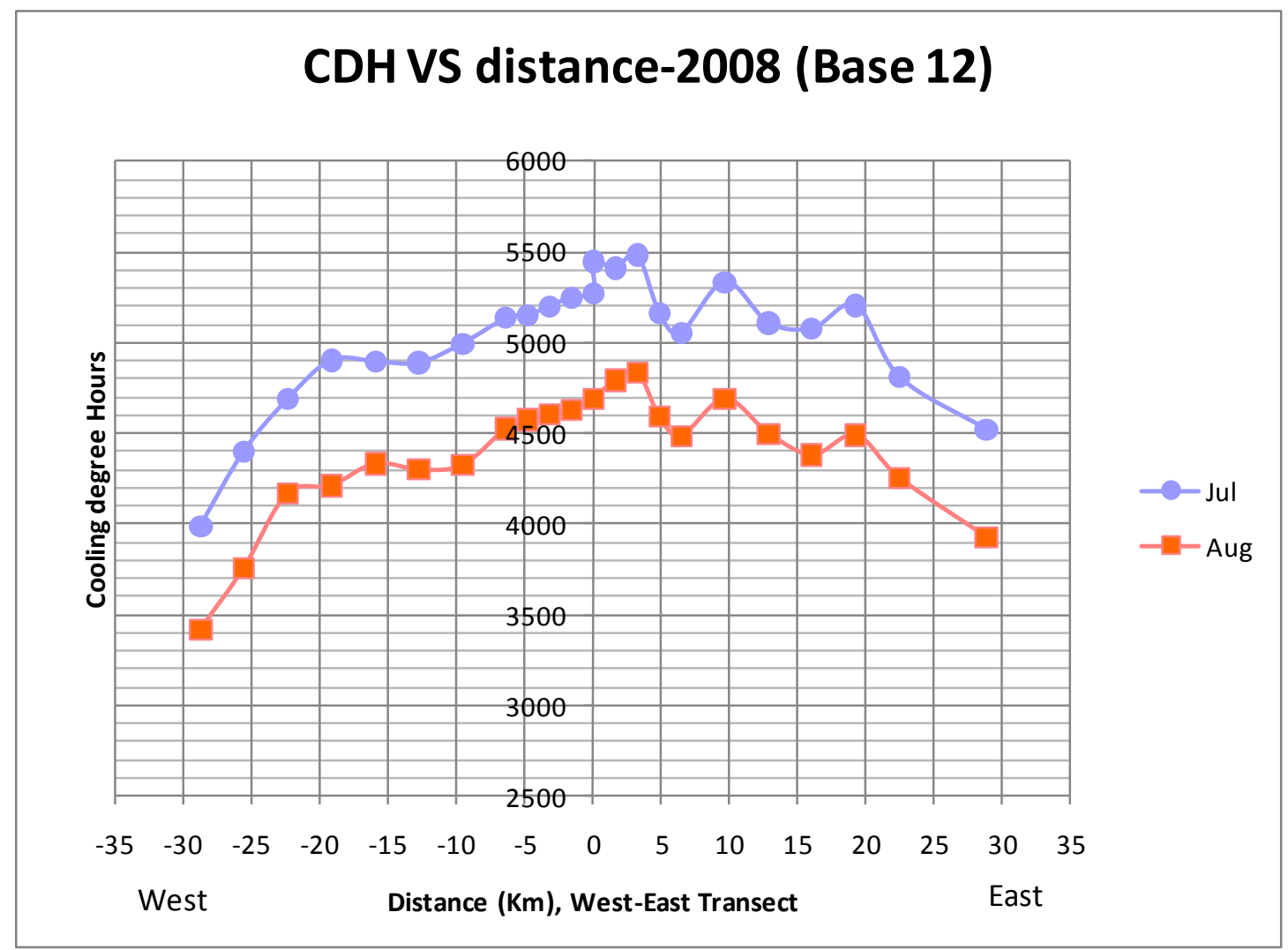

Figure 4: Cooling degree hours for July and August in 2008 (base $12{ }^{\circ} \mathrm{C}$ ) calculated from air temperature predictions using LSSAT. The CDH for Heathrow are 4481 for July and 3974 for August calculated from met data. 


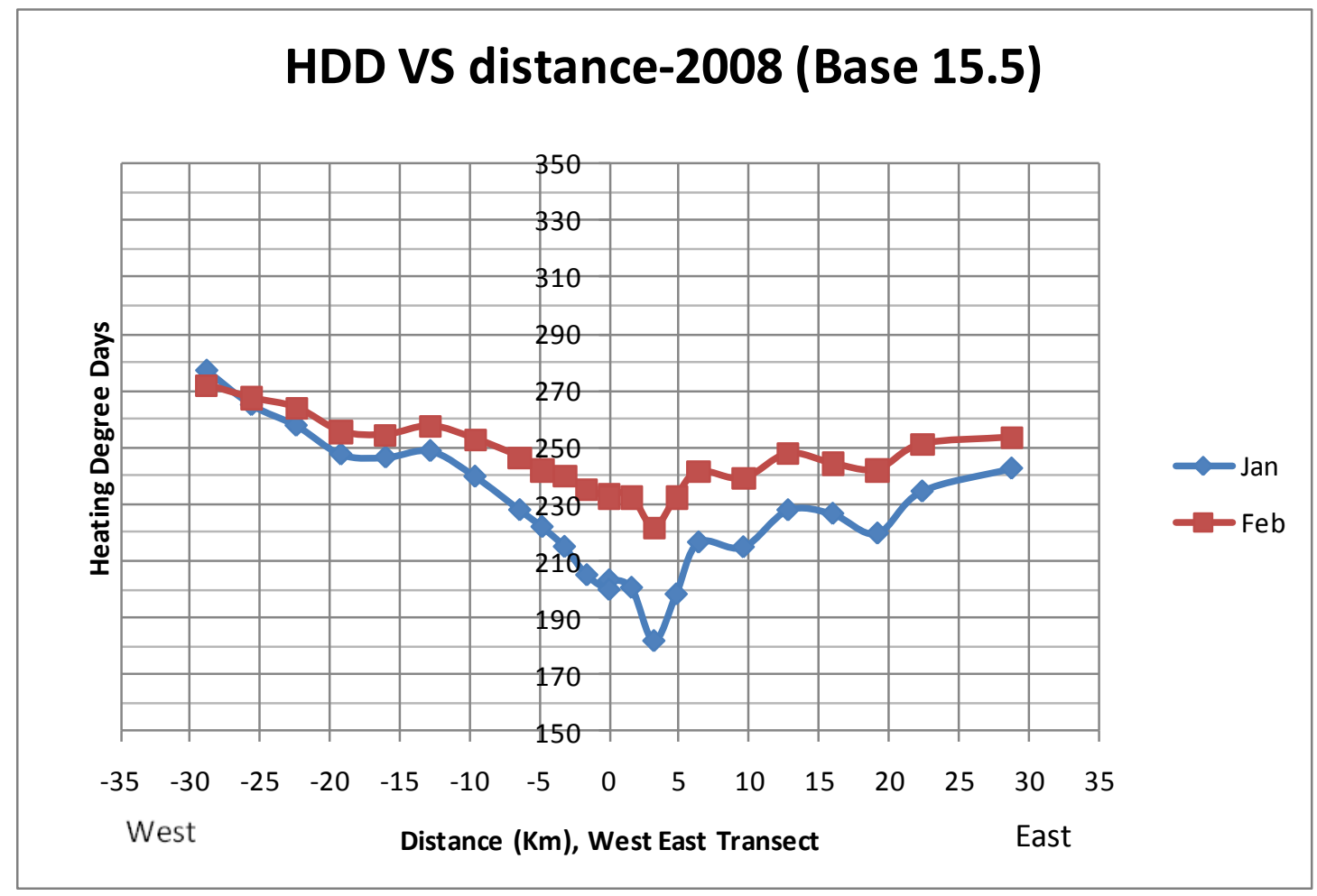

Figure 5: Heating degree days for January and February in 2008 (base $15.5^{\circ} \mathrm{C}$ ) calculated from air temperature predictions using LSSAT. The HDD for Heathrow are 240 for January and 253 for February calculated from met data. 


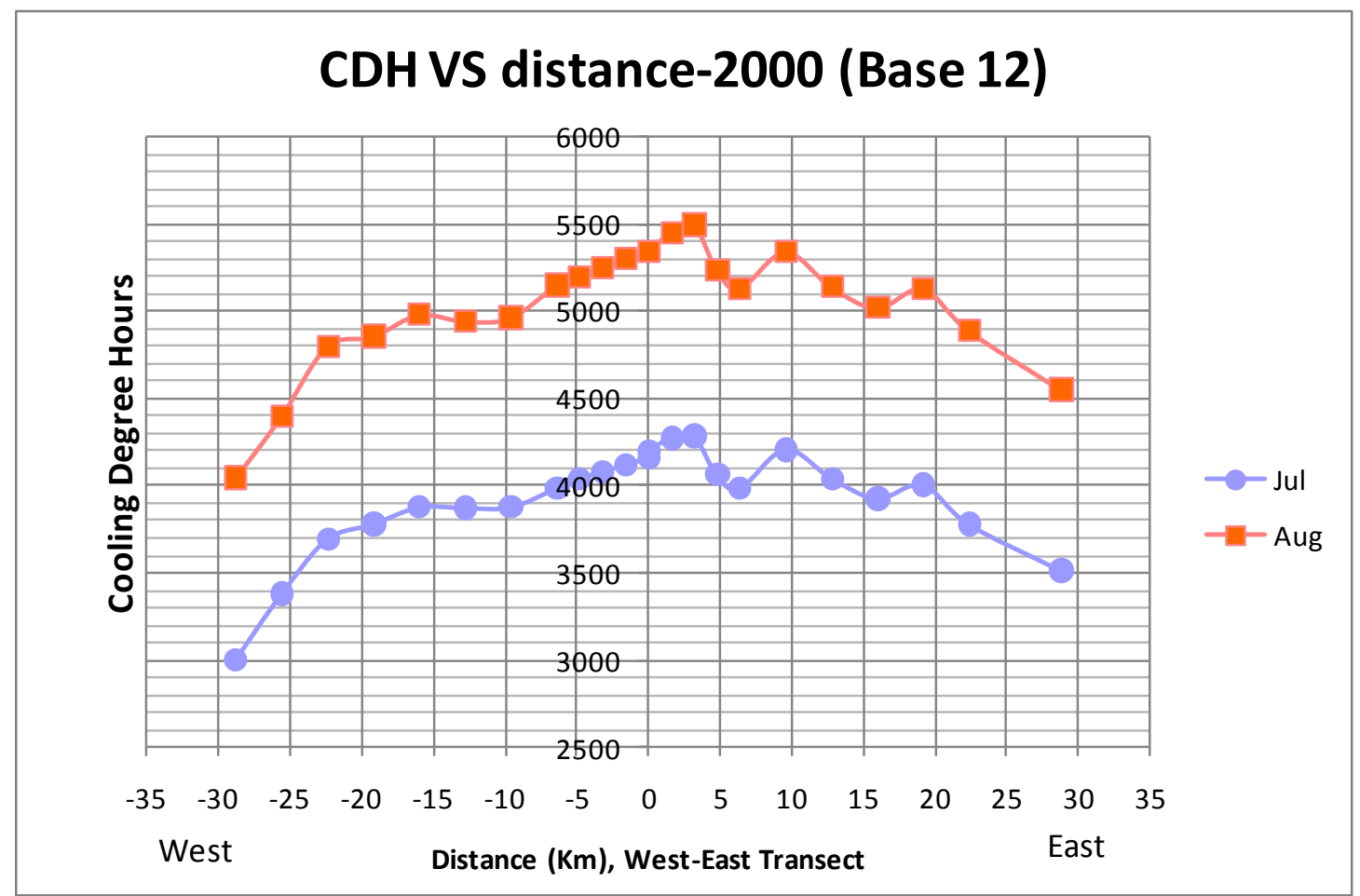

Figure 6: Cooling degree hours for July and August in 2000 (base $12{ }^{\circ} \mathrm{C}$ ) calculated from air temperature predictions using LSSAT. The CDH for Heathrow are 3475 for July and 4590 for August calculated from met data. 


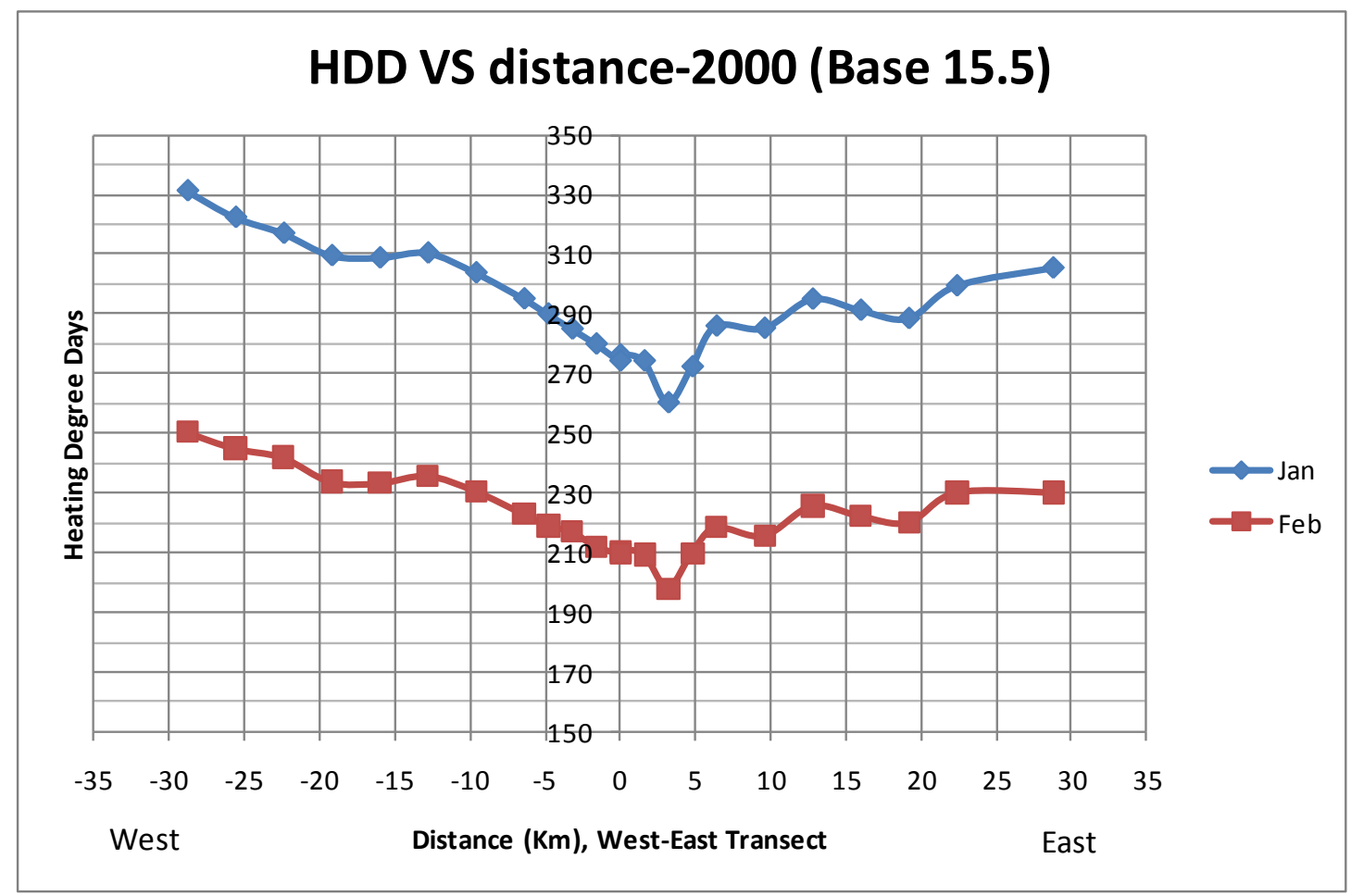

Figure 7: Heating degree days for January and February in 2000 (base $15.5^{\circ} \mathrm{C}$ ) calculated from air temperature predictions using LSSAT. The HDD for Heathrow are 304 for January and 231 for February calculated from met data. 


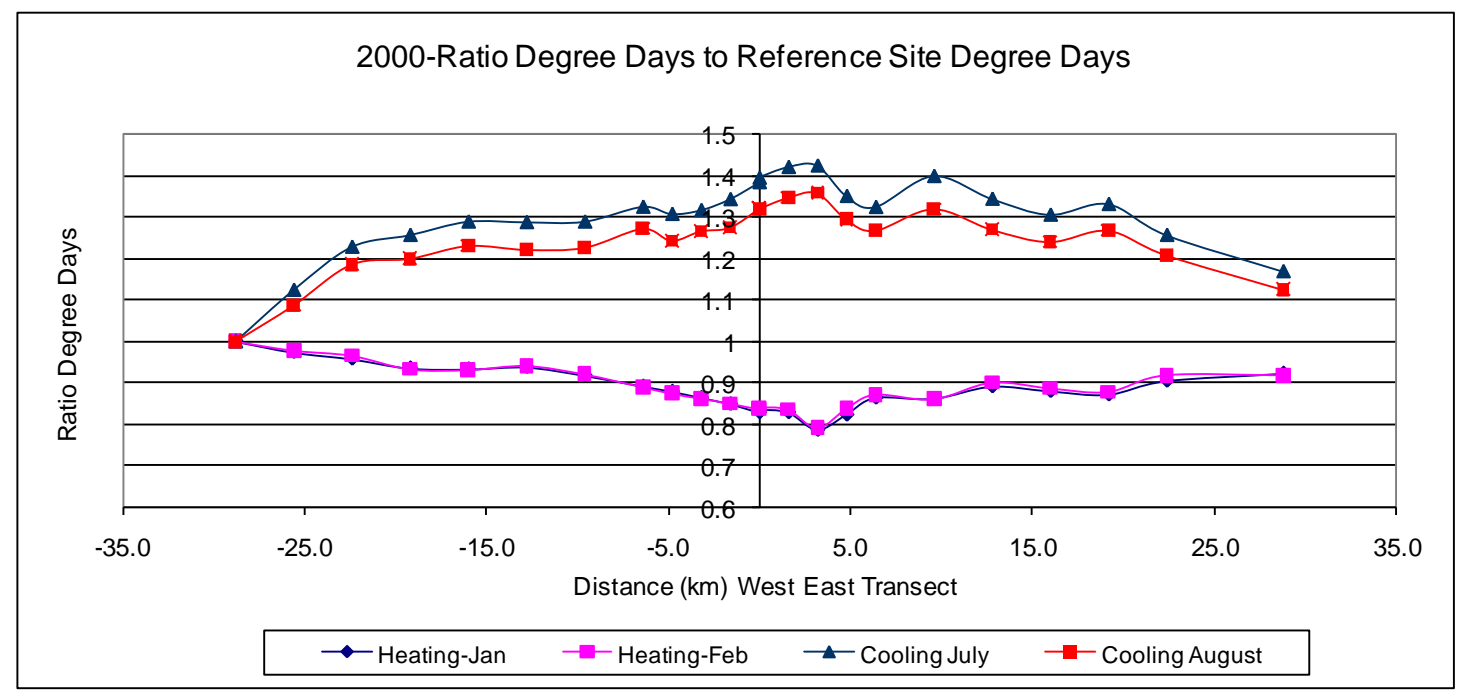

Figure 8: Ratio of Heating and Cooling Degree Days to Reference Site Degree Days for a West-East Transect of London in 2000. The graphs indicates relative heating and cooling energy consumption within the urban heat island compared to the reference rural locations based on air temperature prediction using the model LSSAT. 


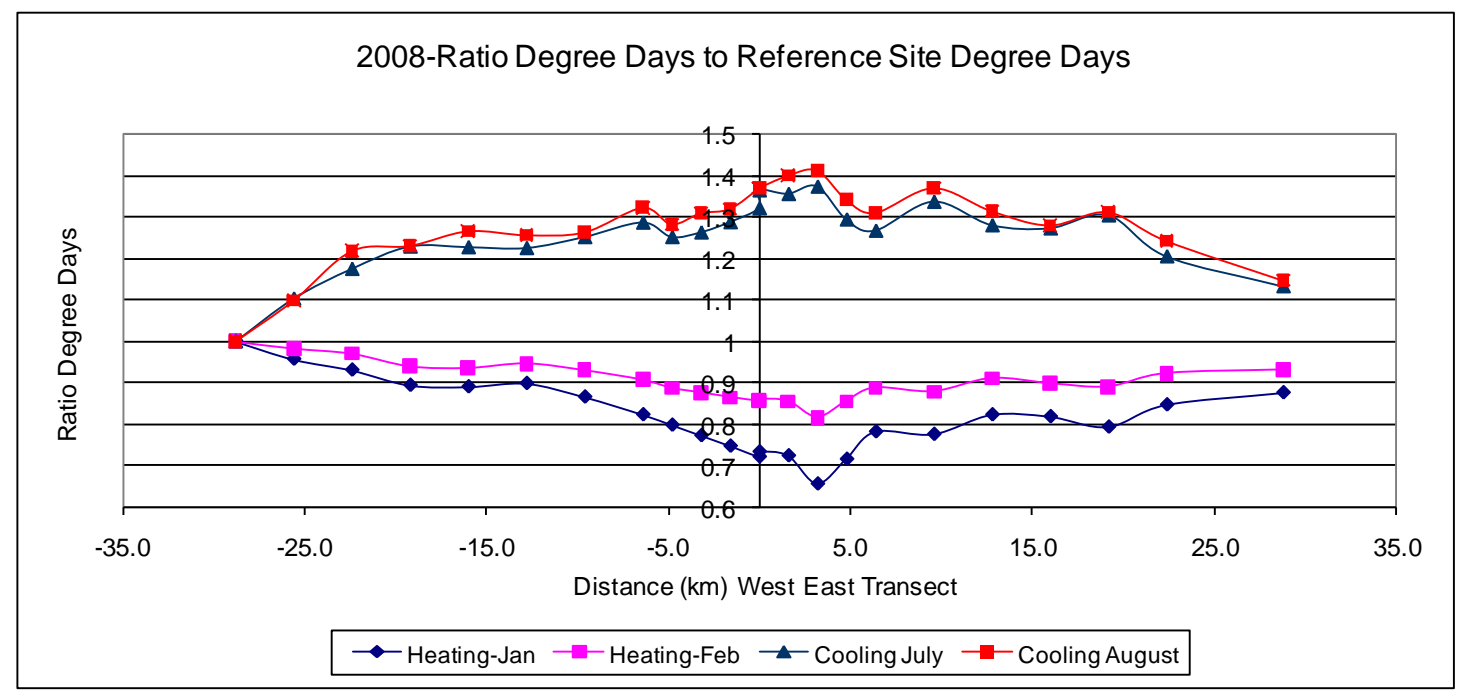

Figure 9: Ratio of Heating and Cooling Degree Days to Reference Site Degree Days for a West-East Transect of London in 2008. The graphs indicates relative heating and cooling energy consumption within the urban heat island compared to the reference rural locations based on air temperature prediction using the model LSSAT. 
Table 1: Parameters used for the development of the LSSAT model.

\begin{tabular}{|l|l|}
\hline Back propagation network & feed-forward \\
\hline Training method & Scaled Conjugate Gradient \\
\hline Error goal & 0.4 \\
\hline Maximum training epoch & 6000 \\
\hline Hidden layer & 1 \\
\hline Number of neurons in hidden layer & 17 \\
\hline
\end{tabular}

Table 2 Summary of the prediction result for hourly LSSAT models (North Road)

\begin{tabular}{|l|l|l|l|l|l|l|l|}
\hline Time & RE & $\mathrm{r}^{2}$ & MSE & Time & RE & $\mathrm{r}^{2}$ & MSE \\
\hline 00:00 & 3.2 & 0.98 & 0.3 & $\mathbf{1 2 : 0 0}$ & 5.4 & 0.99 & 0.6 \\
\hline $\mathbf{0 1 : 0 0}$ & 2.8 & 0.99 & 0.2 & $\mathbf{1 3 : 0 0}$ & 5.5 & 0.99 & 0.6 \\
\hline $\mathbf{0 2 : 0 0}$ & 3.0 & 0.98 & 0.3 & $\mathbf{1 4 : 0 0}$ & 5.6 & 0.99 & 0.6 \\
\hline $\mathbf{0 3 : 0 0}$ & 2.6 & 0.98 & 0.2 & $\mathbf{1 5 : 0 0}$ & 5.3 & 0.98 & 0.6 \\
\hline $\mathbf{0 4 : 0 0}$ & 3.3 & 0.98 & 0.3 & $\mathbf{1 6 : 0 0}$ & 5.4 & 0.99 & 0.6 \\
\hline $\mathbf{0 5 : 0 0}$ & 4.0 & 0.98 & 0.4 & $\mathbf{1 7 : 0 0}$ & 5.4 & 0.98 & 0.6 \\
\hline $\mathbf{0 6 : 0 0}$ & 4.5 & 0.98 & 0.5 & $\mathbf{1 8 : 0 0}$ & 4.8 & 0.99 & 0.5 \\
\hline $\mathbf{0 7 : 0 0}$ & 4.6 & 0.98 & 0.5 & $\mathbf{1 9 : 0 0}$ & 4.2 & 0.99 & 0.4 \\
\hline $\mathbf{0 8 : 0 0}$ & 4.8 & 0.98 & 0.5 & $\mathbf{2 0 : 0 0}$ & 3.2 & 0.99 & 0.3 \\
\hline $\mathbf{0 9 : 0 0}$ & 3.3 & 0.98 & 0.3 & $\mathbf{2 1 : 0 0}$ & 2.5 & 0.99 & 0.2 \\
\hline $\mathbf{1 0 : 0 0}$ & 5.2 & 0.99 & 0.6 & $\mathbf{2 2 : 0 0}$ & 5.5 & 0.97 & 0.6 \\
\hline $\mathbf{1 1 : 0 0}$ & 4.7 & 0.98 & 0.5 & $\mathbf{2 3 : 0 0}$ & 2.7 & 0.99 & 0.2 \\
\hline
\end{tabular}


Table 3: Analysis of comparison between measured and predicted air temperatures for nine locations for July/August and January/February 2008

\begin{tabular}{|c|c|c|c|c|c|c|c|c|c|c|}
\hline & & $\begin{array}{l}\text { Site } \\
1\end{array}$ & $\begin{array}{l}\text { Site } \\
2\end{array}$ & $\begin{array}{l}\text { Site } \\
3\end{array}$ & $\begin{array}{l}\text { Site } \\
4 \\
\end{array}$ & Site 5 & $\begin{array}{l}\text { Site } \\
6\end{array}$ & $\begin{array}{l}\text { Site } \\
7\end{array}$ & $\begin{array}{l}\text { Site } \\
8\end{array}$ & Ref \\
\hline & & 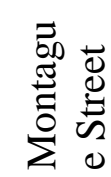 & 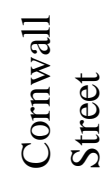 & 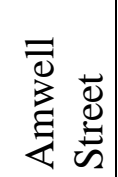 & 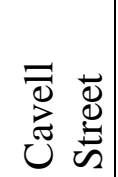 & 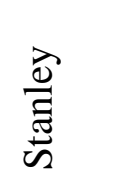 & 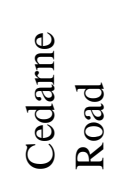 & 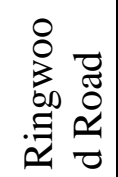 & 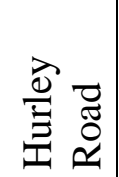 & 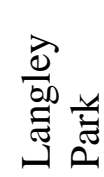 \\
\hline & $\begin{array}{l}\text { Distance } \\
(\mathrm{km})\end{array}$ & 0 & 1.6 & 1.6 & 4.8 & 4.8 & 6.4 & 9.6 & 16 & 29 \\
\hline & Transect & $\mathrm{C}$ & $\mathrm{SE}$ & NW & $\mathrm{EE}$ & $\mathrm{NN}$ & SW & $\mathrm{NE}$ & WW & WW \\
\hline Annual & $\mathrm{r}^{2}$ & - & - & - & - & 0.87 & 0.88 & 0.88 & 0.88 & 0.91 \\
\hline \multirow[t]{5}{*}{ July } & $\mathrm{r}^{2}$ & 0.42 & 0.71 & 0.60 & - & - & 0.70 & 0.55 & 0.65 & 0.76 \\
\hline & Day $\mathrm{r}^{2}$ & 0.26 & 0.52 & 0.34 & - & - & 0.45 & 0.41 & 0.44 & 0.56 \\
\hline & Night $r^{2}$ & 0.58 & 0.79 & 0.83 & - & - & 0.84 & 0.75 & 0.89 & 0.84 \\
\hline & $\begin{array}{l}\text { Avg meas } \\
\text { temperature }\end{array}$ & 19.1 & 19.4 & 19.1 & - & - & 19.0 & 18.9 & 18.4 & 17.4 \\
\hline & $\begin{array}{l}\text { Avg pred } \\
\text { temperature }\end{array}$ & 19.6 & 19.4 & 18.7 & - & - & 19.7 & 19.0 & 18.7 & 17.4 \\
\hline \multirow[t]{5}{*}{ August } & $\mathrm{r}^{2}$ & 0.46 & 0.71 & 0.56 & - & - & 0.70 & 0.65 & 0.63 & 0.74 \\
\hline & Day $r^{2}$ & 0.18 & 0.40 & 0.23 & - & - & 0.35 & 0.38 & 0.29 & 0.49 \\
\hline & Night $r^{2}$ & 0.78 & 0.86 & 0.88 & - & - & 0.84 & 0.77 & 0.88 & 0.88 \\
\hline & $\begin{array}{l}\text { Avg meas } \\
\text { temperature }\end{array}$ & 18.2 & 18.4 & 18.4 & - & - & 18.8 & 17.8 & 17.5 & 16.8 \\
\hline & $\begin{array}{l}\text { Avg pred } \\
\text { temperature }\end{array}$ & 18.3 & 18.4 & 18.1 & - & - & 18.4 & 18.0 & 17.5 & 16.8 \\
\hline \multirow[t]{5}{*}{ January } & $\mathrm{r}^{2}$ & - & - & - & - & 0.62 & 0.72 & 0.70 & 0.72 & 0.81 \\
\hline & Day $\mathrm{r}^{2}$ & - & - & - & - & 0.61 & 0.84 & 0.75 & 0.82 & 0.83 \\
\hline & Night $r^{2}$ & - & - & - & - & 0.93 & 0.92 & 0.92 & 0.92 & 0.91 \\
\hline & $\begin{array}{l}\text { Avg meas } \\
\text { temperature }\end{array}$ & - & - & - & - & 6.9 & 7.3 & 6.5 & 6.4 & 5.5 \\
\hline & $\begin{array}{l}\text { Avg pred } \\
\text { temperature }\end{array}$ & - & - & - & - & 6.8 & 7.0 & 6.8 & 6.4 & 5.8 \\
\hline \multirow[t]{5}{*}{ February } & $\mathrm{r}^{2}$ & 0.50 & 0.53 & 0.45 & 0.55 & 0.62 & 0.72 & 0.70 & 0.72 & 0.81 \\
\hline & Day $r^{2}$ & 0.48 & 0.53 & 0.52 & 0.61 & 0.54 & 0.72 & 0.69 & 0.68 & 0.78 \\
\hline & Night $r^{2}$ & 0.71 & 0.82 & 0.81 & 0.71 & 0.82 & 0.75 & 0.90 & 0.75 & 0.82 \\
\hline & $\begin{array}{l}\text { Avg meas } \\
\text { temperature }\end{array}$ & - & - & - & - & 6.9 & 7.3 & 6.5 & 6.4 & 5.5 \\
\hline & $\begin{array}{l}\text { Avg pred } \\
\text { temperature }\end{array}$ & - & - & - & - & 6.8 & 7.0 & 6.8 & 6.4 & 5.8 \\
\hline \multirow[t]{5}{*}{ Heathrow } & 2008 & Jan & Feb & Jul & Aug & 2000 & Jan & Feb & Jul & Aug \\
\hline & Avg air temp & 7.8 & 6.5 & 18.0 & 17.3 & & 5.7 & 7.2 & 16.6 & 18.2 \\
\hline & Wind speed & 5.9 & 4.2 & 4.4 & 4.9 & & 3.1 & 3.7 & 2.6 & 3.0 \\
\hline & Cloud cover & 5.4 & 3.6 & 4.7 & 5.9 & & 5.6 & 5.6 & 5.8 & 5.0 \\
\hline & Avg Sol Rad & 30 & 72 & 212 & 146 & & 31 & 58 & 172 & 179 \\
\hline
\end{tabular}


